Case Report

\title{
Hepatitis B Virus Reactivation Induced by Infliximab Administration in a Patient with Crohn's Disease
}

\author{
Yuka Miyake, ${ }^{1}$ Aki Hasebe, ${ }^{2}$ Tetsuya Tanihira, ${ }^{1}$ Akiko Shiraishi, ${ }^{1}$ \\ Yusuke Imai, ${ }^{1}$ Haruka Tatsukawa, ${ }_{1}^{1}$ Hiroka Yamago, ${ }^{1}$ Hiromasa Nakahara, ${ }^{1}$ \\ Yuko Shimizu, ${ }^{1}$ Keiko Ninomiya, ${ }^{1}$ Atsushi Hiraoka, ${ }^{1}$ Hideki Miyata, ${ }^{1}$ \\ Tomoyuki Ninomiya, ${ }^{1}$ and Kojiro Michitaka ${ }^{1}$ \\ ${ }^{1}$ Gastroenterology Center, Ehime Prefectural Central Hospital, Kasugamachi 83, Matsuyama, Ehime 790-0024, Japan \\ ${ }^{2}$ Internal Medicine, Saiseikai Imabari Hospital, Imabari 799-1502, Japan \\ Correspondence should be addressed to Kojiro Michitaka; kojiromichitaka@gmail.com
}

Received 26 April 2013; Accepted 21 May 2013

Academic Editors: M. Deutsch, F. Imazeki, G. H. Koek, F. Pérez Roldán, and M. Vigano

Copyright ( 2013 Yuka Miyake et al. This is an open access article distributed under the Creative Commons Attribution License, which permits unrestricted use, distribution, and reproduction in any medium, provided the original work is properly cited.

\begin{abstract}
A 47-year-old man diagnosed with Crohn's disease was treated with infliximab. He tested negative for hepatitis B surface antigen (HBsAg) and hepatitis B surface antibody (anti-HBs) but positive for anti-HB core antibody (anti-HBc). He tested positive for hepatitis B virus (HBV-) DNA 3 months after treatment and was administered entecavir. HBV-DNA test showed negative results 1 month later. ALT was persistently within the normal range, and HBV-DNA was persistently negative thereafter despite the continuation of infliximab every 8 weeks. In our hospital, 14 patients with inflammatory bowel disease, who tested negative for HBsAg, were treated with infliximab; 2 of them tested positive for anti-HBs and/or anti-HBc, and HBV reactivation was observed in 1 patient (the present patient). The present case and these findings highlight that careful follow-up is needed in patients with inflammatory bowel disease treated with infliximab who test positive for anti-HBc and/or anti-HBs.
\end{abstract}

\section{Introduction}

Crohn's disease is a chronic and intractable inflammatory disorder of the gastrointestinal tract [1]. Many types of therapy have been introduced to treat Crohn's disease, such as nutritional therapy, 5-aminosalicylic acid drugs, corticosteroids, azathioprine, and 6-mercaptopurine [2-6]. Monoclonal antibodies against tumor necrosis factor alpha (anti-TNF $\alpha$ ), such as infliximab and adalimumab, have recently been used to treat inflammatory bowel disease [7-9]. Short- and long-term anti-TNF- $\alpha$ therapies in Crohn's disease are generally well tolerated. However, clinicians must be vigilant for the occurrence of infrequent but serious events [10].

Immunosuppressive therapy may induce the reactivation of hepatitis $B$ virus (HBV), not only in patients in an inactive hepatitis B surface antigen ( $\mathrm{HBsAg}$ ) carrier state, but, in resolved patients as well. HBV reactivation in HBV-resolved patients may cause hepatitis (i.e., de novo hepatitis). Moreover, hepatitis $\mathrm{B}$ reactivation due to immunosuppressive therapy sometimes progresses to severe hepatitis, and several fatal cases have been reported $[11,12]$.

Here, we report the case of a patient with Crohn's disease who tested negative for $\mathrm{HBsAg}$ and positive for anti-HB core antibody (anti-HBc) and exhibited HBV reactivation during treatment with anti-TNF- $\alpha$ antibody (infliximab).

\section{Case Report}

A 47-year-old man, with a history of abdominal operations because of perforation of the ileum and ileus in 2000 and 2001, respectively, and diagnosed with Crohn's disease histologically in 2000, was admitted to our hospital because of abdominal pain. He was diagnosed with intestinal stricture of the ascending colon due to Crohn's disease (Figure 1). He was treated by resection of the ascending colon, followed by treatment with anti-TNF- $\alpha$ (i.e., infliximab). The patient was negative for HBsAg, hepatitis B surface antibody (anti-HBs), 


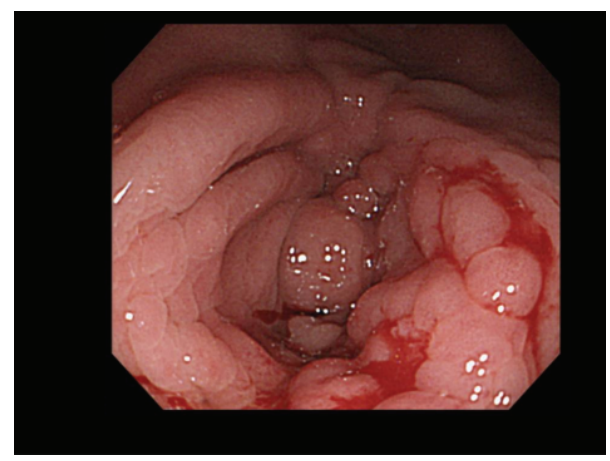

FIGURE 1: Photograph of lower endoscopic examination. A longitudinal ulcer scar, a cobblestone appearance, and stenosis were observed at the hepatic flexure.

and HBV-DNA, but positive for anti-HBc upon admission (Table 1). He was examined for HBV-DNA monthly after the start of infliximab. HBV-DNA was assayed by quantitative real-time polymerase chain reaction. Infliximab at $5 \mathrm{mg} / \mathrm{kg}$ body weight was administered. Infliximab was scheduled to be administered 2 and 6 weeks after the first administration, and then every 8 weeks. His symptoms improved after the beginning of treatment. He tested positive for HBV-DNA 3 months after the beginning of treatment (after 3 injections) (Figure 2). Although he had no symptoms and his alanine aminotransferase (ALT) level was within the normal range, he was administered entecavir according to the Japanese Guidelines [13]. HBV-DNA test showed negative results 1 month later. ALT was persistently within the normal range and HBV-DNA was persistently negative thereafter despite the continuation of infliximab every 8 weeks.

In our hospital, 15 patients with inflammatory bowel diseases (including Behçet's disease) have been treated with infliximab. A list of patients and their HBV markers is shown in Table 1. One patient was positive for HBsAg; he was diagnosed as having an inactive HBsAg carrier state. Entecavir was administered from the beginning of infliximab administration (Table 2). Among the other 14 patients who tested negative for HBsAg, 2 tested positive for anti-HBc and/or anti-HBs. One was positive for both anti-HBs and anti-HBc, and the other (the present patient) was positive for only anti$\mathrm{HBc}$. Both patients were assayed for HBV-DNA monthly, and HBV-DNA reactivation was observed in the present patient.

\section{Discussion}

$\mathrm{HBV}$ reactivation is one of the major problems in patients receiving immunosuppressive therapy or chemotherapy against malignant tumors. Approximately 350 million and 3 billion people worldwide are infected with HBV chronically and transiently, respectively. They have a risk of reactivation of HBV if they receive these therapies. The American Association for the Study of Liver Diseases Practice Guidelines indicate that the rates of $\mathrm{HBV}$ reactivation in transiently infected people (i.e., those negative for HBsAg and positive for anti-HBc and/or anti-HBs) receiving mild, moderate, and
TABLE 1: Laboratory data on admission.

\begin{tabular}{|c|c|c|c|c|c|}
\hline Urine & & & BUN & 12.4 & $\mathrm{mg} / \mathrm{dL}$ \\
\hline Protein & $(-)$ & & Creatinine & 1.34 & $\mathrm{mg} / \mathrm{dL}$ \\
\hline Sugar & $(-)$ & & $\mathrm{Na}$ & 136 & $\mathrm{mEq} / \mathrm{L}$ \\
\hline Blood & $(-)$ & & $\mathrm{K}$ & 4.3 & $\mathrm{mEq} / \mathrm{L}$ \\
\hline \multirow[t]{2}{*}{ Urobil. } & $( \pm)$ & & $\mathrm{Cl}$ & 105 & $\mathrm{mEq} / \mathrm{L}$ \\
\hline & & & $\mathrm{Ca}$ & 8.1 & $\mathrm{mg} / \mathrm{dL}$ \\
\hline WBC & 4300 & $/ \mu \mathrm{L}$ & Amylase & 169 & IU/L \\
\hline $\mathrm{RBC}$ & $359 \times 10^{4}$ & $/ \mu \mathrm{L}$ & & & \\
\hline $\mathrm{Hb}$ & 11.5 & $\mathrm{~g} / \mathrm{dL}$ & CRP & 3.75 & $\mathrm{mg} / \mathrm{dL}$ \\
\hline $\mathrm{Ht}$ & 33.1 & $\%$ & & & \\
\hline \multirow[t]{2}{*}{ Platelet } & $20.1 \times 10^{4}$ & $/ \mu \mathrm{L}$ & $\mathrm{PT}$ & 89.1 & $\%$ \\
\hline & & & PT (INR) & 1.05 & \\
\hline T. protein & 6.4 & $\mathrm{~g} / \mathrm{dL}$ & & & \\
\hline Alb. & 3.4 & $\mathrm{~g} / \mathrm{dL}$ & HBsAg & $(-)$ & CLIA \\
\hline T. bil. & 0.3 & $\mathrm{mg} / \mathrm{dL}$ & Anti-HBs & $(-)$ & CLIA \\
\hline AST & 42 & IU/L & Anti-HBc & (+) 1.62 & CLIA \\
\hline ALT & 45 & $\mathrm{IU} / \mathrm{L}$ & HBV-DNA & $(-)$ & Real-time PCR \\
\hline ALP & 348 & $\mathrm{IU} / \mathrm{L}$ & Anti-HCV & $(-)$ & CLIA \\
\hline $\mathrm{CHE}$ & 238 & IU/L & & & \\
\hline$\gamma$-GTP & 56 & $\mathrm{IU} / \mathrm{L}$ & & & \\
\hline
\end{tabular}

PCR: polymerase chain reaction; CLIA: chemiluminescence immunoassay.

intense immunosuppressive therapy are $1.0-2.7 \%, 12 \%$, and $14-20 \%$, respectively, [14].

Recently, anti-TNF- $\alpha$ has been widely used in patients with rheumatoid arthritis, psoriatic arthritis, ulcerative colitis, Crohn's disease, and ankylosing spondylitis. The risk of $\mathrm{HBV}$ reactivation under anti-TNF $\alpha$ administration has been studied, but the actual risk remains controversial. Several reports emphasize the risk of reactivation. Urata et al. studied HBV reactivation in patients with rheumatoid arthritis who received various therapies, and found that 17 of 135 patients experienced reactivation; moreover, the use of biologic agents was significantly more frequent in patients who developed HBV-DNA reactivation than in patients who did not [15]. Another report indicates that the risk of reactivation is higher with infliximab administration than with other anti-TNF- $\alpha$ agents [16]. On the other hand, several reports indicate the safety of anti-TNF- $\alpha$ agents [17]. Tamori et al. report that none of the 21 patients with rheumatoid arthritis who received infliximab experienced reactivation [18]. The majority of these studies were performed on patients with rheumatoid arthritis, and the information regarding its risk in patients with inflammatory bowel disease is scarce. The immune state may be different between patients with rheumatoid arthritis and those with inflammatory bowel disease; therefore, it is needed to clarify this issue in patients with inflammatory bowel disease. There are a few reports that described the risk of severe hepatitis in patients with Crohn's disease treated with anti-TNF- $\alpha$ agents; however, information was still insufficient [19-23]. In the present study, 1 out of 2 patients with Crohn's disease with resolved hepatitis exhibited reactivation. The exact rates of reactivation due to specific anti-TNF- $\alpha$ 


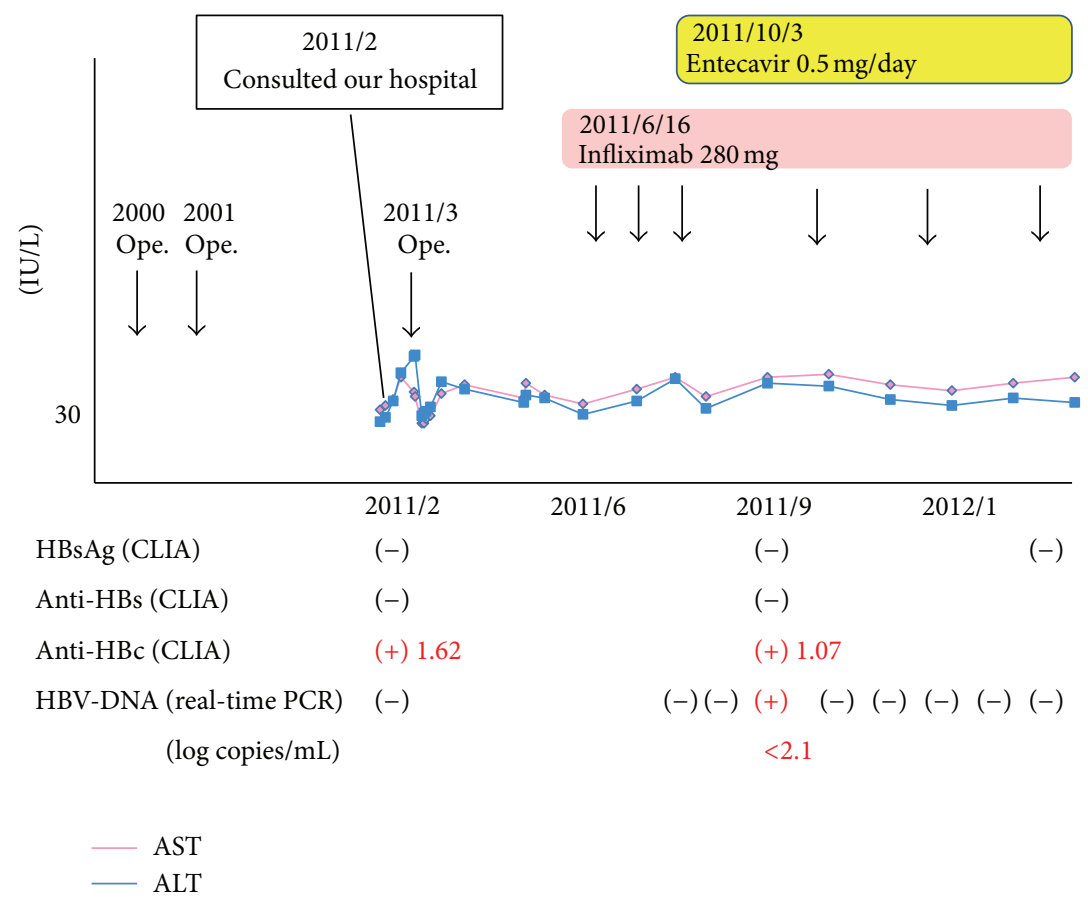

FIGURE 2: Clinical course. HBV-DNA and ALT levels were screened every month after the start of infliximab.

TABLE 2: HBV markers in patients treated with infliximab.

\begin{tabular}{|c|c|c|c|c|c|c|c|}
\hline Age & Sex & & HBsAg & Anti-HBs & Anti-HBc s/co & HBV reactivation & Entecavir \\
\hline 47 & $\mathrm{~F}$ & Crohn & $(+)$ & & & & $(+)$ \\
\hline 54 & $\mathrm{~F}$ & Crohn & $(-)$ & $(+)$ & $(+) 6.41$ & $(-)$ & $(-)$ \\
\hline 47 & M & Crohn & $(-)$ & $(-)$ & (+) 1.62 & $(+)$ & $(+)$ \\
\hline 55 & $\mathrm{~F}$ & Crohn & $(-)$ & $(-)$ & $(-) 0.9$ & & \\
\hline 64 & $\mathrm{~F}$ & UC & $(-)$ & $(-)$ & $(-) 0.09$ & & \\
\hline 19 & M & Crohn & $(-)$ & $(-)$ & $(-) 0.05$ & & \\
\hline 34 & M & Crohn & $(-)$ & $(-)$ & $(-) 0.11$ & & \\
\hline 52 & $\mathrm{~F}$ & UC & $(-)$ & $(-)$ & $(-) 0.07$ & & \\
\hline 43 & M & Crohn & $(-)$ & $(-)$ & $(-) 0.09$ & & \\
\hline 38 & M & Behçet & $(-)$ & $(-)$ & $(-) 0.11$ & & \\
\hline 52 & M & UC & $(-)$ & $(-)$ & $(-) 0.08$ & & \\
\hline 18 & $\mathrm{~F}$ & Crohn & $(-)$ & $(-)$ & $(-) 0.05$ & & \\
\hline 42 & M & Crohn & $(-)$ & $(-)$ & $(-) 0.15$ & & \\
\hline 41 & M & UC & $(-)$ & $(-)$ & $(-) 0.07$ & & \\
\hline 23 & M & Crohn & $(-)$ & $(-)$ & $(-) 0.14$ & & \\
\hline
\end{tabular}

Crohn: Crohn's disease, UC: ulcerative colitis, Behçet: Behçet's disease, M: male, F: female.

agents (e.g., infliximab, adalimumab, and etanercept) should be clarified in the future.

Kato et al. studied which HBV markers are related to HBV reactivation in patients who received immunosuppressive therapy and found that a low titer of baseline anti-HBs may increase the risk [22]. In the present study, 2 patients displayed markers for resolved hepatitis B; one patient tested positive for anti-HBc and negative for anti-HBs experienced reactivation and the other patient was positive for both anti-HBc and anti-HBs did not experience reactivation. The present findings are concordant with those of Kato et al.
The present patient was administered entecavir immediately when HBV-DNA became positive with very low level. It has been recommended by the Japanese Guidelines [13] that entecavir should be administrated when HBV-DNA became positive in patients treated with immunosuppressive agents, but it is still controversial whether entecavir should be administrated immediately when HBV-DNA became positive with a very low level (or positive only by qualitative assay). This issue should be further investigated.

There is a shortage of information regarding the prevalence of $\mathrm{HBV}$ markers in patients with inflammatory bowel 
disease. Reports from France and Spain indicate that the prevalence of HBV markers in patients with inflammatory bowel disease is similar to that in the general population [24, 25]. In the present study, 3 out of 15 patients displayed markers of present or past HBV infection; 1 was positive for $\mathrm{HBsAg}$, and 2 (13.3\%) were positive for anti-HBc and/or anti-HBs and negative for HBsAg. There are too few patients in the present study to adequately discuss this issue. However, it must be noted that a considerable percentage of patients with inflammatory bowel disease display HBV markers. Therefore, HBV markers including anti-HBs and anti-HBc should be examined in patients who are scheduled for anti-TNF- $\alpha$ treatment, and careful follow-up is needed after the beginning of antiTNF- $\alpha$ administration if any HBV markers are positive.

\section{Conflict of Interests}

The authors declare that they have no conflict of interests.

\section{References}

[1] K. Asakura, Y. Nishiwaki, N. Inoue, T. Hibi, M. Watanabe, and T. Takebayashi, "Prevalence of ulcerative colitis and Crohn's disease in Japan," Journal of Gastroenterology, vol. 44, no. 7, pp. 659-665, 2009.

[2] M. H. Alhagamhmad, A. S. Day, D. A. Lemberg et al., "An update of the role of nutritional therapy in the management of Crohn's disease," Journal of Gastroenterology, vol. 47, pp. 872-882, 2012.

[3] T. Matsui, T. Sakurai, and T. Yao, "Nutritional therapy for Crohn's disease in Japan," Journal of Gastroenterology, vol. 40, supplement 16, pp. 25-31, 2005.

[4] M. J. Carter, A. J. Lobo, and S. P. L. Travis, "Guidelines for the management of inflammatory bowel disease in adults," Gut, vol. 53, supplement 5, pp. vl-v16, 2004.

[5] P. Juillerat, V. Pittet, C. Mottet et al., "Appropriateness of early management of newly diagnosed Crohn's disease in a European population-based cohort," Scandinavian Journal of Gastroenterology, vol. 45, no. 12, pp. 1449-1456, 2010.

[6] G. R. Lichtenstein, S. B. Hanauer, and W. J. Sandborn, "Practice parameters committee of the American College of Gastroenterology. Management of Crohn's disease in adults," The American Journal of Gastroenterology, vol. 104, pp. 465-483, 2009.

[7] H. Imaeda, A. Andoh, and Y. Fujiyama, "Development of a new immunoassay for the accurate determination of anti-infliximab antibodies in inflammatory bowel disease," Journal of Gastroenterology, vol. 47, pp. 136-143, 2012.

[8] A. Papa, G. Mocci, M. Bonizzi et al., "Use of infliximab in particular clinical settings: management based on current evidence," The American Journal of Gastroenterology, vol. 104, no. 6, pp. 1575-1586, 2009.

[9] D. T. Rubin, R. Panaccione, J. Chao, and A. M. Robinson, “A practical, evidence-based guide to the use of adalimumab in Crohn's disease," Current Medical Research and Opinion, vol. 27, no. 9, pp. 1803-1813, 2011.

[10] G. R. Lichtenstein, B. G. Feagan, R. D. Cohen et al., "Serious infection and mortality in patients with Crohn's disease: more than 5 years of follow-up in the TREAT registry," The American Journal of Gastroenterology, vol. 107, pp. 1409-1422, 2012.

[11] T. Sera, Y. Hiasa, K. Michitaka et al., "Anti-HBs-positive liver failure due to hepatitis $B$ virus reactivation induced by Rituximab," Internal Medicine, vol. 45, no. 11, pp. 721-724, 2006.
[12] A. Sako, H. Yasunaga, H. Horiguchi, H. Hashimoto, N. Masaki, and S. Matsuda, "Acute hepatitis B in Japan: incidence, clinical practices and health policy," Hepatology Research, vol. 41, no. 1, pp. 39-45, 2011.

[13] M. Oketani, A. Ido, H. Uto et al., "Prevention of hepatitis B virus reactivation in patients receiving immunosuppressive therapy or chemotherapy," Hepatology Research, vol. 42, pp. 627-636, 2012.

[14] A. S. F. Lok and B. J. McMahon, “Chronic hepatitis B," Hepatology, vol. 45, no. 2, pp. 507-539, 2007.

[15] Y. Urata, R. Uesato, D. Tanaka et al., "Prevalence of reactivation of hepatitis B virus replication in rheumatoid arthritis patients," Modern Rheumatology, vol. 21, no. 1, pp. 16-23, 2011.

[16] R. Pérez-Alvarez, C. Díaz-Lagares, F. García-Hernández et al., "Hepatitis B virus (HBV) reactivation in patients receiving tumor necrosis factor (TNF)-targeted therapy: analysis of 257 cases," Medicine, vol. 90, pp. 359-371, 2011.

[17] R. Caporali, F. Bobbio-Pallavicini, F. Atzeni et al., "Safety of tumor necrosis factor $\alpha$ blockers in hepatitis B virus occult carriers (hepatitis B surface antigen negative/anti-hepatitis B core antigen positive) with rheumatic diseases," Arthritis Care and Research, vol. 62, no. 6, pp. 749-754, 2010.

[18] A. Tamori, T. Koike, H. Goto et al., "Prospective study of reactivation of hepatitis B virus in patients with rheumatoid arthritis who received immunosuppressive therapy: evaluation of both HBsAg-positive and HBsAg-negative cohorts," Journal of Gastroenterology, vol. 46, no. 4, pp. 556-564, 2011.

[19] M. Esteve, C. Saro, F. González-Huix, F. Suarez, M. Forné, and J. M. Viver, "Chronic hepatitis B reactivation following infliximab therapy in Crohn's disease patients: need for primary prophylaxis," Gut, vol. 53, no. 9, pp. 1363-1365, 2004.

[20] K. Ojiro, M. Naganuma, H. Ebinuma et al., "Reactivation of hepatitis B in a patient with Crohn's disease treated using infliximab," Journal of Gastroenterology, vol. 43, no. 5, pp. 397-401, 2008.

[21] S. Madonia, A. Orlando, D. Scimeca, M. Olivo, F. Rossi, and M. Cottone, "Occult hepatitis B and infliximab-induced HBV reactivation," Inflammatory Bowel Diseases, vol. 13, no. 4, pp. 508-509, 2007.

[22] M. Kato, T. Atsumi, T. Kurita et al., "Hepatitis B virus reactivation by immunosuppressive therapy in patients with autoimmune diseases: risk analysis in hepatitis B surface antigennegative cases," Journal of Rheumatology, vol. 38, no. 10, pp. 2209-2214, 2011.

[23] C. Loras, J. P. Gisbert, M. Mínguez et al., "Liver dysfunction related to hepatitis $\mathrm{B}$ and $\mathrm{C}$ in patients with inflammatory bowel disease treated with immunosuppressive therapy," Gut, vol. 59, no. 10, pp. 1340-1346, 2010.

[24] J.-B. Chevaux, A. Nani, A. Oussalah et al., "Prevalence of hepatitis $\mathrm{B}$ and $\mathrm{C}$ and risk factors for nonvaccination in inflammatory bowel disease patients in Northeast France," Inflammatory Bowel Diseases, vol. 16, no. 6, pp. 916-924, 2010.

[25] C. Loras, C. Saro, F. Gonzalez-Huix et al., "Prevalence and factors related to hepatitis B and C in inflammatory bowel disease patients in Spain: a nationwide, multicenter study," The American Journal of Gastroenterology, vol. 104, pp. 57-63, 2009. 


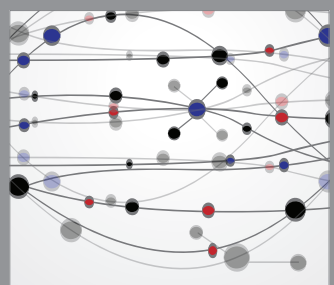

The Scientific World Journal
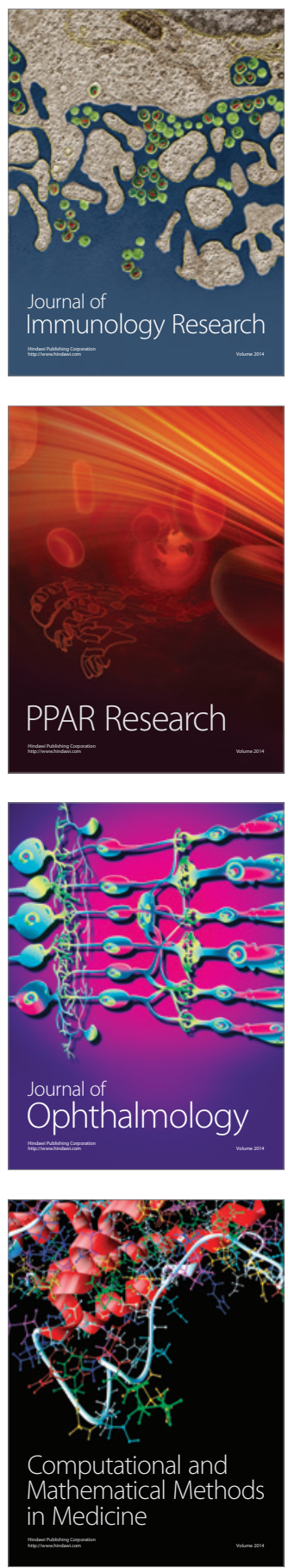

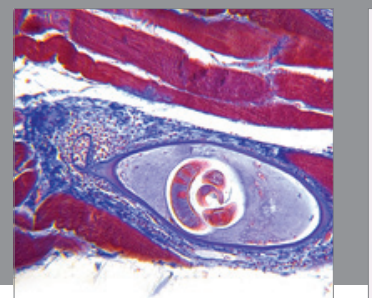

Gastroenterology

Research and Practice
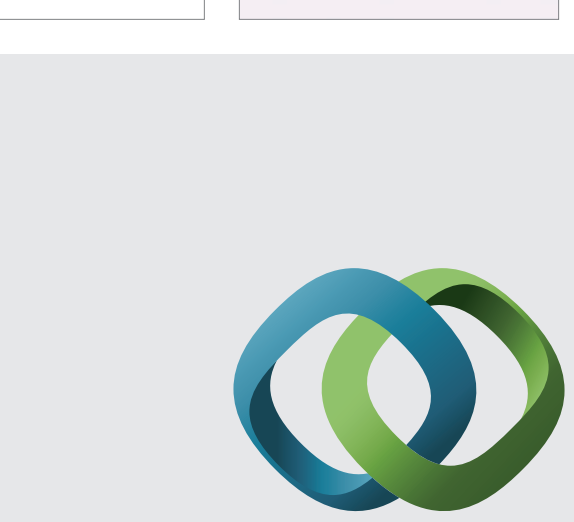

\section{Hindawi}

Submit your manuscripts at

http://www.hindawi.com
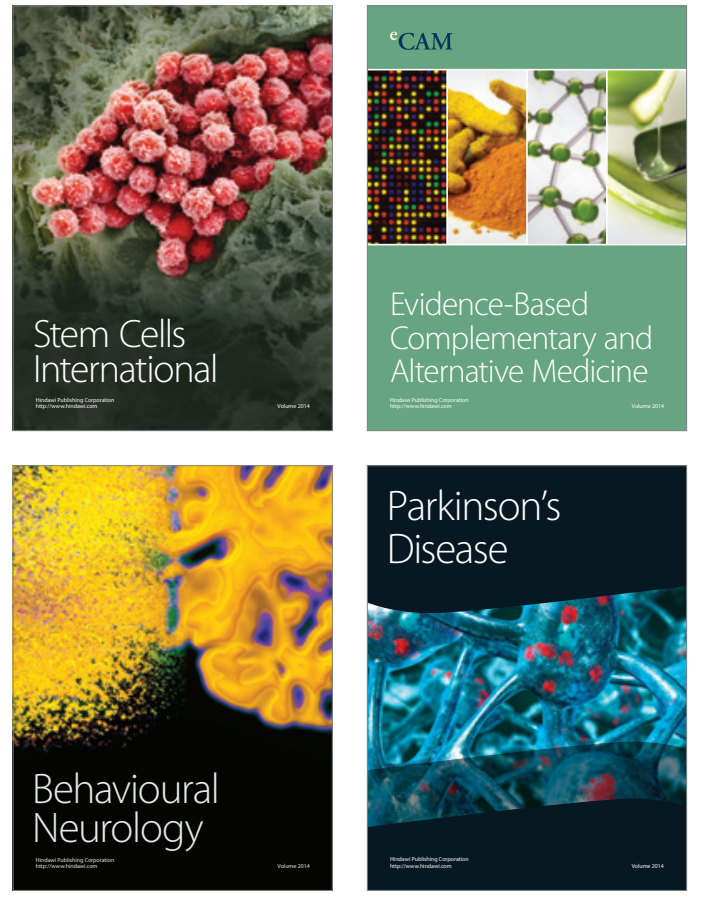
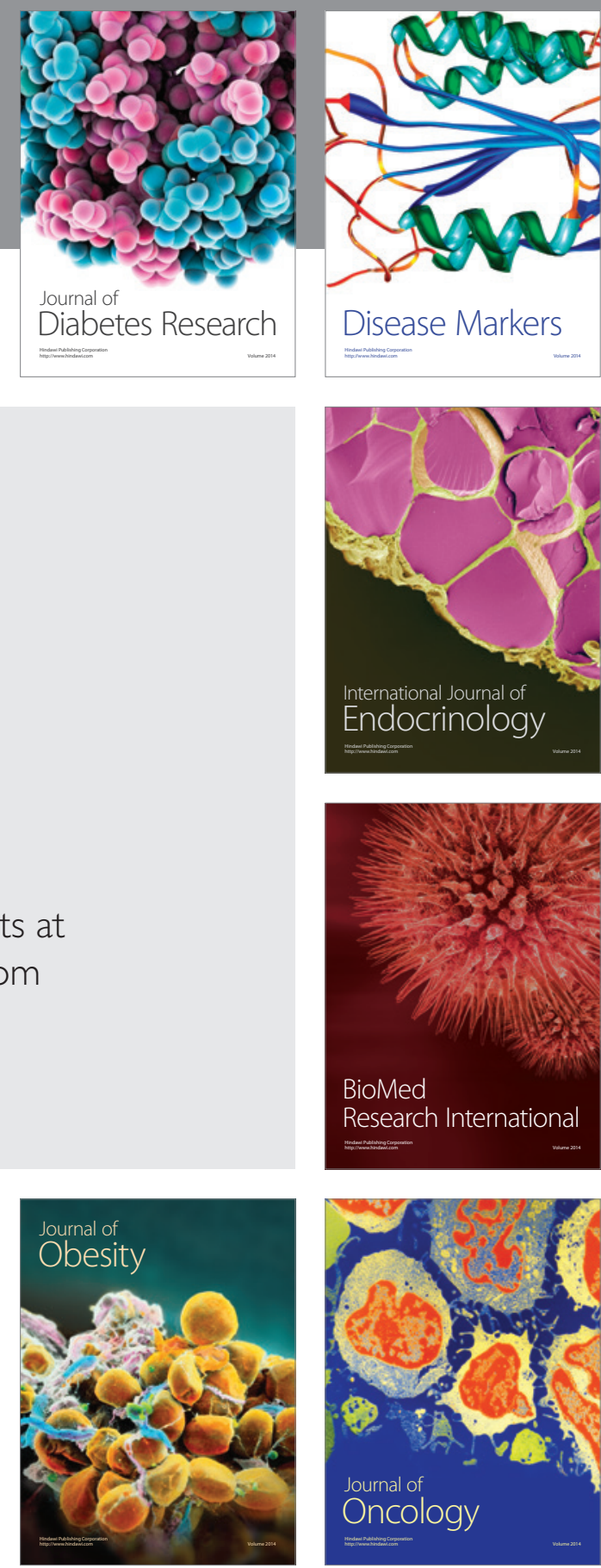

Disease Markers
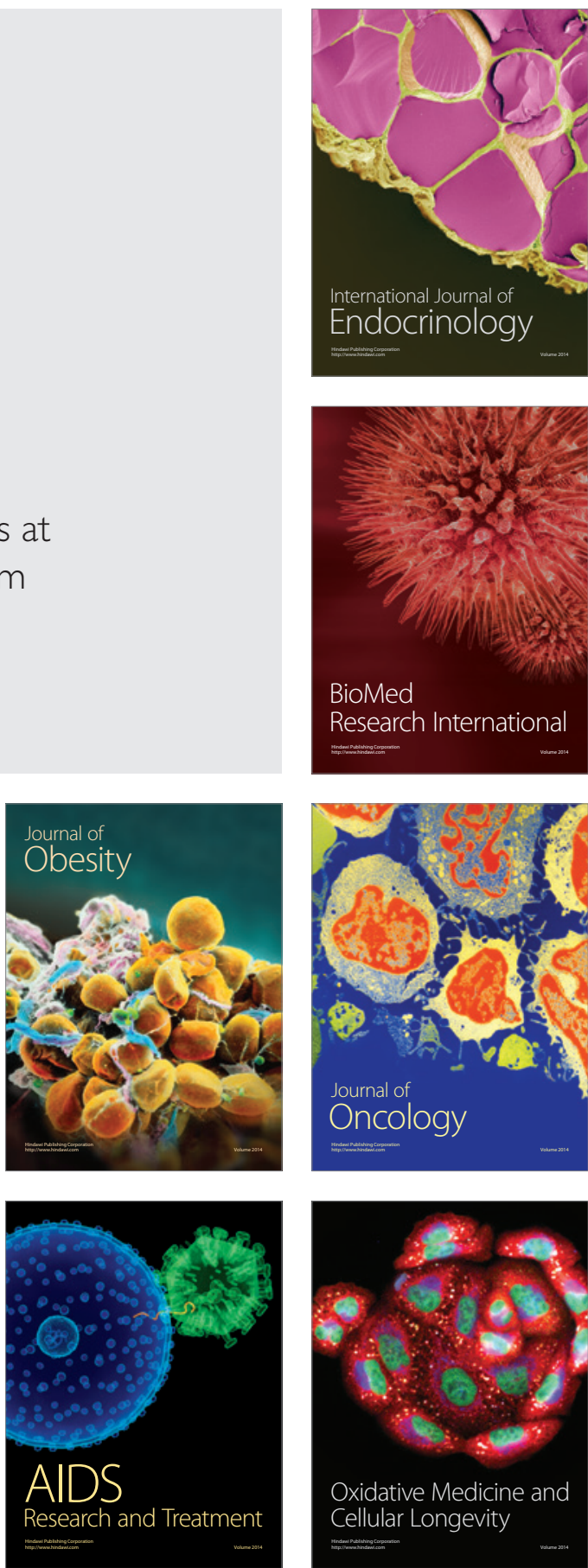